\title{
КОГНИТИВНЫЕ ОСОБЕННОСТИ ЯЗЫКА ПЕРЕГОВОРОВ НА ПРИМЕРЕ ТЕКСТОВ ХУДОЖЕСТВЕННЫХ ФИЛЬМОВ
}

\section{COGNITIVE FEATURES OF THE NEGOTIATION LANGUAGE ON THE EXAMPLE OF TEXTS OF FEATURE FILMS}

\section{Philippova}

T. Shikhalkina

Summary: From the perspective of cognitive linguistics, some features of the negotiation language are considered on the example of replicas from feature films; the main tasks of understanding the functions of negotiators are highlighted; preliminary conclusions are made about the theoretical and practical solution of the problem of communication during commercial negotiations

Key words: cognitive, negotiation, communication, discourse.

\author{
Филиппова Маргарита Михайловна \\ К.филол.н., доцент, Московский государственный \\ университет им. М. В. Ломоносова \\ philippova.marga@gmail.com \\ Шихалкина Татьяна Григорьевна \\ Аспирант, Московский государственный университет \\ им. М. В. Ломоносова \\ shikhalkina@gmail.com
}

Аннотация: С позиции когнитивной лингвистики рассматриваются некоторые особенности языка переговоров на примере реплик из художественных фильмов; выделены основные задачи понимания функций участников переговоров; сделаны предварительные выводы о теоретическом и практическом решении проблемы коммуникации во время коммерческих переговоров.

Ключевые слова: когнитивный, переговоры, коммуникация, дискурс.

Согласно А.А. Кибрику, лингвистические формы отражают то, как человек мыслит, то есть строение сознания и когнитивное состояние индивида. К числу важнейших когнитивных особенностей, определяющих форму дискурса, относят особенности передачи знаний, естественную категоризацию, длительную память, оперативную память, уровень внимания и активности. [6]. Когнитивная лингвистика исходит из того, что языковая форма зависит от лингвистических функций, важнейшими и определяющими из которых провозглашаются когнитивные функции (коммуникативные установки, семантические поля, иллокутивные цели), а остальные языковые функции являются производными, либо сводимы к ним.

Когнитивная сторона дискурса имеет большое значение, так как именно она влияет на дискурс, определяя его форму [2]. Так как различные культурные и социальные системы во многом объясняют речевые особенности человека, необходимо при этом учитывать «экстралингвистические» сферы жизни. Культура и социальность влияют на дискурс через мышление говорящего, определяемое его когнитивной, языковой и риторической компетенцией.

Дискурс - составляющая социокультурной интеракции, определяющейся интересами, целями и личным речевым стилем говорящего. Выбор возможных тем речи часто определяется общекультурными знаниями [3]. Переговорный дискурс является одной из наиболее сложных разновидностей именно с когнитивной точки зрения, что подтверждается рекомендациями авторов 
пособий по языку переговоров, например: «Переговорные тактики, которые вы можете использовать: *Не показывайте свой интерес к покупке; *Сделайте слегка удивленный вид, услышав цену; *Затем притворитесь, что вы думали, что товар не столь дорогой; * Подчеркните, что этот товар - не совсем то, что вы искали; *Притворитесь, что вы видели аналогичный товар по более низкой цене; *Притворитесь, что у вас с собой недостаточно денег; * Скажите, что вы подумаете об этом и сделайте вид, что собираетесь уходить. Однако не перестарайтесь, не то упустите выгодную сделку» [10]. При этом, как это ни парадоксально, во многих пособиях по ведению переговоров речь идет о том, как добиться доверительных отношений. Таким образом, можно говорить о когнитивном конфликте или когнитивном парадоксе переговорного дискурса, когда, с одной стороны, вам требуется культивировать доверительные отношения с вашим визави, а с другой - специалисты рекомендуют вам постоянно притворяться.

И даже учитывая то, что честность и открытость являются ключевыми в деловой коммуникации, иногда стремление к установлению собственных условий влечет за собой применение сторонами широкого спектра стратегий и тактик, включая тактику strategic misrepresentation (т.е. искажение фактов в собственных целях, проще говоря - ложь), о преподавании которой в Гарварде профессором Г. Райффой говорит в своей книге Уильям Сафайр: «Профессор обучает правилам принятия коммуникативных решений, поднимая вопрос о необходимости дипломата говорить неправду в целях достижения необходимых договоренностей: это важно, чтобы обучающиеся осознавали неизбежность ситуаций, ставящих их в уязвимое положение. Они должны понимать последствия своего решения честно раскрыть информацию, которая может быть использована противниками, чтобы дискредитировать их». [11]. Поэтому для большей корректности интерпретирования коммуникации необходимо проводить анализ цели и когнитивной составляющей высказывания, на которые влияют лингвистические и экстралингвистические психологические факторы.

Бизнес-переговоры - это осознанное намерение индивида или группы через дискурс побудить другого индивида или группу к действию в целях изменения к лучшему ситуации или установления нового уровня отношений между участниками коммуникации.

Чтобы глубже понять речевой жанр бизнес-переговоров, мы обратились к идеям М.М. Бахтина [1] и других ученых: Halliday, Martin, Ventola, Christie, John Swales, B. Paltridge и др. Следует подчеркнуть, что данный вид коммуникации находится сегодня в динамичном состоянии и является изменчивым и незавершенным. Становление жанра деловых переговоров как части дискурса и самого явления как процесса человеческого взаимодействия определяется социальными факторами.

В основном жанр деловых переговоров охватывает ситуации производства, бизнеса, политические и военные коммуникации. Как показывают наблюдения, сегодня многие руководители и деловые люди убедились в том, что нужно уметь использовать формы и методы словесного воздействия на основе рекомендаций риторики, психологии, этики и социологии. Следует отметить роль эвфемизмов как инструмента когнитивного рефрейминга, то есть представления ситуации выгодным для одной из сторон образом. Например, во время кубинского кризиса 60-х гг., когда мир был на грани ядерной катастрофы, США организовали морскую блокаду Кубы, но дали этому название «карантин», что звучит гораздо менее угрожающе [8]. Яркие примеры рефрейминга приводит С. Пинкер: «вторжение в Ирак» в отличие от «освобождения Ирака», «прерывание беременности» по контрасту с «убийством нерожденного ребенка», «перераспределение богатства» в отличие от «конфискации доходов». [9] Многие споры в человеческих делах зависят не от данных или логики, а от того, какой фрейм выбран для репрезентации некоторого факта.

Деловые коммерческие переговоры, анализируемые в нашей работе, характеризуются, как правило, ярко выраженной экспрессивностью, обоюдным желанием сторон повлиять друг на друга и на ход переговоров (воздействие), избежать конфликта, договориться (прийти к определенному соглашению) и извлечь при этом для себя определенную выгоду.

Переговоры - это общение, и его эффективность зависит от коммуникативных навыков сторон, таким образом дискурс влияет на результат, делая возможным или невозможным достижение коммуникативной цели. Основная цель дипломата - убедить собеседника выслушать его идеи и убедить его в необходимости принятия условий. С точки зрения когнитивной лингвистики, понимание - это логическое завершение акта коммуникации. Действие активно. Реципиент, воспринимая лингвистический смысл речи, одновременно является активным участником дискурса: он волен согласиться с предложением оппонента или отвергнуть его (полностью или частично), свободен дополнить речь и сделать контрпредложение, и эта позиция принадлежит ему с начала и до конца. Важно установить цель коммуникации, речь не всегда буквальна, и всегда существует скрытый контекст, доступный обеим сторонам и не выражаемый буквально.

Сначала оппонент воспринимает общую лингвистическую структуру дискурса, затем определяет тактику и структуру мысли говорящего через конкретную комму 
никативную ситуацию.

В.3. Демьянков приводит девять основных задач понимания:

1. Применение лингвистических знаний.

2. Понимание структуры и значения речи собеседника, одновременно с разворачиванием дискурса во времени. Например: I have something to tell you. If you want to pay by your credit card... I can decrease it to seven ... Sixteen each.

3. Понимание сказанного. Через внешнюю структуру высказывания мы восстанавливаем структуру мышления оппонента, стараясь воссоздать то, что он не высказал вербально. Например: I'm not saying that what you do isn't important. Avery and I appreciate you, and Liddy just adores you.

4. Понимание замысла оппонента: момент осмысления настоящих и ложных интенций автора речи. Как пример: I know your interest and excitement in this product is greater than the amount you're offering.

5. Осознание различий между внутренним и модельным мирами. Следует обращать внимание на те моменты в речи собеседника, где нарушается целостность и связность уже полученной нами картины сообщаемого. Например: You understand my confusion. I'm actually paying you more money to be here half the time. I'm not saying that what you do isn't important.

6. Осознание отношений внутри модельного и вну- треннего миров. Речь идет при этом об установлении внутренних связей между различными событиями в речи собеседника, в том числе, в его аргументации. Например: My point is that we value what you do, but this rate is unreasonable.

7. Соотнесение модельного мира с запасом знаний слушающего. Поняв текст, мы информационно обогащаемся. Например: Steven has approached me at least several times. The ND there gave me his number. They'll make me a better offer. It's a five-minute drive.

8. Соотнесение понимания с линией поведения слушающего.

9. Выбор тональности понимания, ключ. Необходимо стремиться воспринять обращенные к нам слова как сказанные с добрыми намерениями в наших же интересах и удерживать эту тональность понимания даже при гипотезах о противоположном [5, С. 56-65].

Деловая общественность на современном этапе социального и экономического развития возлагает большие надежды на коммуникативный процесс, в ходе которого достигаются диалог и взаимопонимание людей, разделенных экономическими, политическими, идеологическими, культурными границами. Поэтому актуальной остается задача преодолеть барьеры традиционных схем и расширить знания о процессах деловой коммуникации в терминах когнитивистики и прагматики.

1. Бахтин М.М. Эстетика словесного творчества. М.: Искусство, 1979.

2. Баранов А.Г. Текст в функционально-прагматической парадигме. Краснодар, КубГУ, 1988.

3. Дейк Т.А. Ван. Язык. Познание. Коммуникация. М.: Прогресс, 1989.

4. Дейк Т.А. Ван, Кинч В. Стратегии понимания связного текста // Новое в зарубежной лингвистике. Вып.23, М.: Прогресс, 1988. С. $153-211$.

5. Демьянков В.3. Недопонимание как нарушение социальных предписаний // Язык и социальное познание: Сб. науч. ст. / АН СССР. М., 1990. С. 56-65.

6. ибрик А.А. Когнитивные исследования по дискурсу // Вопросы языкознания. 1994. № 5. С. 126-139.

7. The discourse of negotiation: Studies of Language in the Workplace / Ed. by Alan Firth. Oxford, etc.: Pergamon, 1995. - XV.

8. Malhotra D. Negotiating the Impossible. How to Break Deadlocks and Resolve Ugly Conflicts (without money or muscle). Berrett-Koehler Publishers, Inc. Oakland, CA. 2016.

9. Pinker S. The Stuff of Thought. Language as a Window into Human Nature. Penguin Books, 2007.

10. Powell M. International Negotiations. CUP, 2015.

11. Safire W. William Safire on Language. Avon Books. New York, 1981.

12. Warren Martin. Inexplicitness. A Feature of Naturalness in Conversation // Text and Technology. University of Lulea, Sweden. 1987. PP. 37-53. 